\title{
REUFIS - ustanovljena mednarodna povezava za invazivne vrste $v$ gozdovih na območju Evrope in Srednje Azije
}

\section{Andreja KAVČIČ ${ }^{\text {* }}$}

Od 17. do 19. oktobra 2017 je v Budimpešti na Madžarskem potekalo inavguracijsko srečanje »Forest Invasive Species Network for Europe and Central Asia (REUFIS) meeting «, ki ga je organizirala organizacija Združenih Narodov za hrano in kmetijstvo (FAO - Food and Agriculture Organization of the United Nations), Regionalni urad za Evropo in Srednjo Azijo. Na poziv Ministrstva za kmetijstvo gozdarstvo in prehrano, Direktorata za gozdarstvo, se je srečanja udeležil tudi Gozdarski inštitut Slovenije, Oddelek za varstvo gozdov, z namenom aktivne vključitve Slovenije $\mathrm{v}$ povezavo REUFIS.

Zaradi povečevanja obsega mednarodne trgovine, globalizacije in klimatskih sprememb, je vnos tujerodnih vrst na gozdove vse večji, gozdovi pa postajajo tudi bolj dovzetni za negativne vplive invazivnih organizmov. Invazivne vrste ne poznajo meja, zato je pri upravljanju s temi organizmi za preprečevanje oz. omejevanje njihovih negativnih vplivov ključno povezovanje ne samo med inštitucijami na nacionalni ravni, ampak tudi aktivno sodelovanje med različnimi državami.

Praksa kaže, da je komunikacija na področju invazivnih vrst tako na nacionalni ravni kot tudi na mednarodni ravni nezadostna oz. neučinkovita, kar onemogoča učinkovito preprečevanje vnosa in omejevanje širjenja invazivnih vrst ter zmanjševanje njihovih negativnih vplivov v gozdovih.
Zaradi tega je bila leta 2015 dana pobuda za vzpostavitev mednarodne povezave na območju Evrope in Srednje Azije, ki bi omogočala izmenjavo informacij, izkušenj in dobrih praks, čezmejno sodelovanje v raziskovalnih in drugih aktivnostih ter usklajeno izvajanje fitosanitarnih predpisov na področju invazivnih vrst v gozdovih na tem območju. Septembra 2016 je FAO Regionalni urad za Evropo in Srednjo Azijo organiziral prvi REUFIS sestanek, ki se ga je udeležilo 23 držav iz Evrope in Srednje Azije in na katerem je bila vzpostavitev povezave REUFIS tudi uradno potrjena. Podobne povezave že obstajajo za Afriko (FISNA), Azijo in Pacifik (APFISN), Bližnji Vzhod (NENFHIS) in Južno Ameriko (Red de Países del Cono Sur sobre Especies Exoticas Invasoras a Ecosistemas Forestales).

Inavguracijskega srečanja na Madžarskem se je udeležilo 47 udeležencev iz 25 držav: Armenija, Azerbajdžan, Belorusija, Bosna in Hercegovina, Bolgarija, Češka, Francija, Gruzija, Hrvaška, Italija, Latvija, Madžarska, Moldavija, Norveška, Poljska, Romunija, Ruska federacija, Srbija, Slovaška, Slovenija, Španija, Švedska, Tadžikistan, Ukrajina in Uzbekistan. Udeleženci smo bili različnih strokovnih profilov in smo prihajali z ministrstev, univerz in inštitutov. Prisotni so bili tudi predstavniki FAO in Evropske in mediteranske organizacije za varstvo rastlin (EPPO - European and Mediterranean Plant Protection Organization) (slika 1).

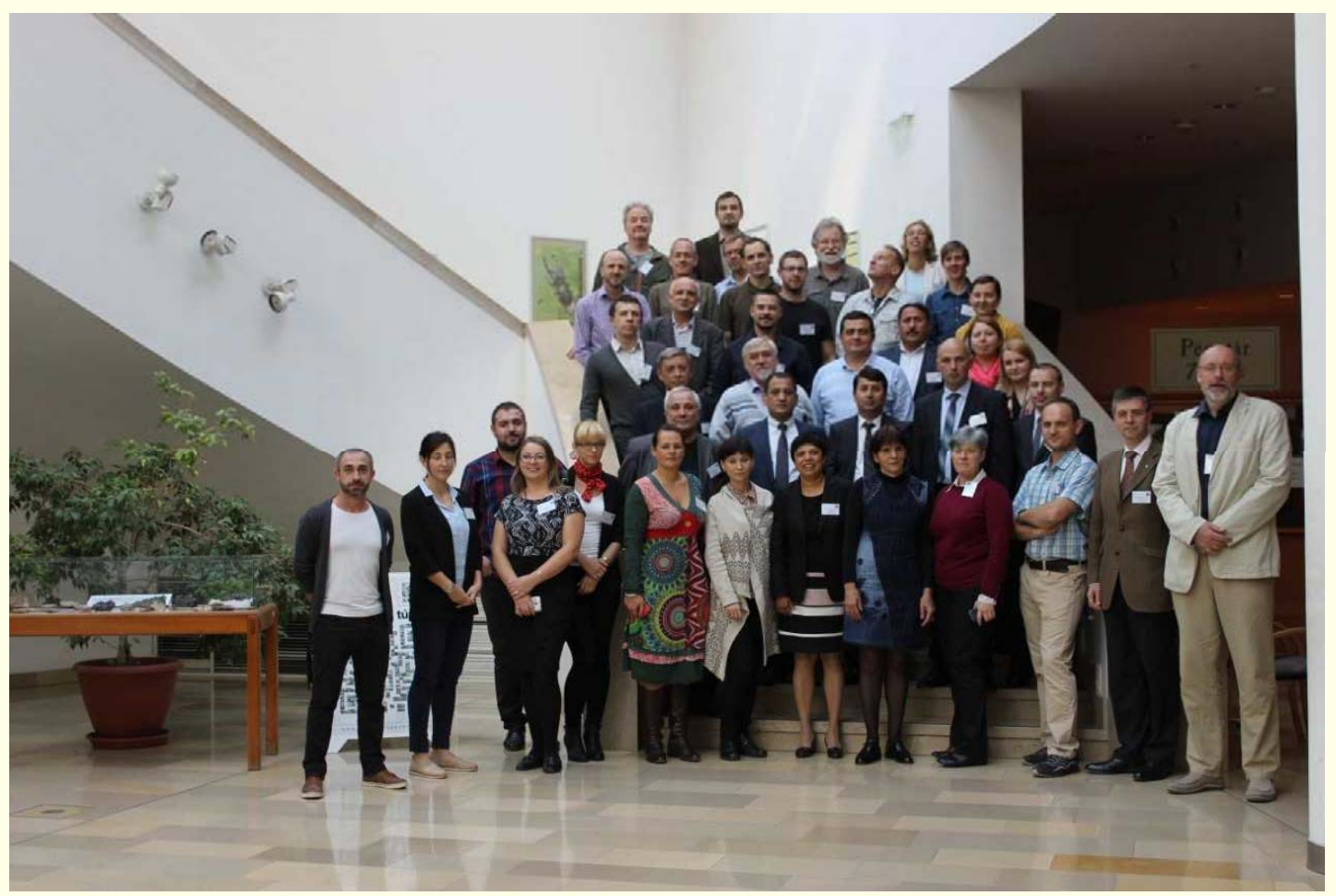

Slika 1: Udeleženci inavguracijskega srečanja REUFIS (vir: FAO) 
Srečanje je bilo sestavljeno iz teoretičnega, praktičnega in terenskega dela. Prvi dan smo se seznanili s problematiko invazivnih vrst $\mathrm{v}$ gozdovih na območju Evrope in Srednje Azije. Največ škode v gozdovih na tem območju povzročajo različne fitofagne vrste žuželk, predvsem podlubniki in defoliatorji, zato je bila na to temo organizirana tudi delavnica. Delavnica je bila $\mathrm{v}$ prostorih prirodoslovnega muzeja, vodil pa jo je dr. Jiri Hulcr, eden največjih strokovnjakov za invazivne vrste podlubnikov z Univerze na Floridi, ki nas je seznanil z biologijo in ekologijo podlubnikov, ki so eni najpomembnejših škodljivcev v gozdovih v svetovnem merilu. Udeleženci smo bili še posebej navdušeni nad praktičnim delom, ki je vključeval delo z referenčnimi zbirkami, kjer smo se z uporabo lup na konkretnih primerkih več kot 30 najnevarnejših vrst podlubnikov učili osnov prepoznavanja morfoloških značilnosti posameznih družin, rodov in vrst. Preostala dva dneva srečanja sta potekala na Ministrstvu za kmetijstvo (slika 2).

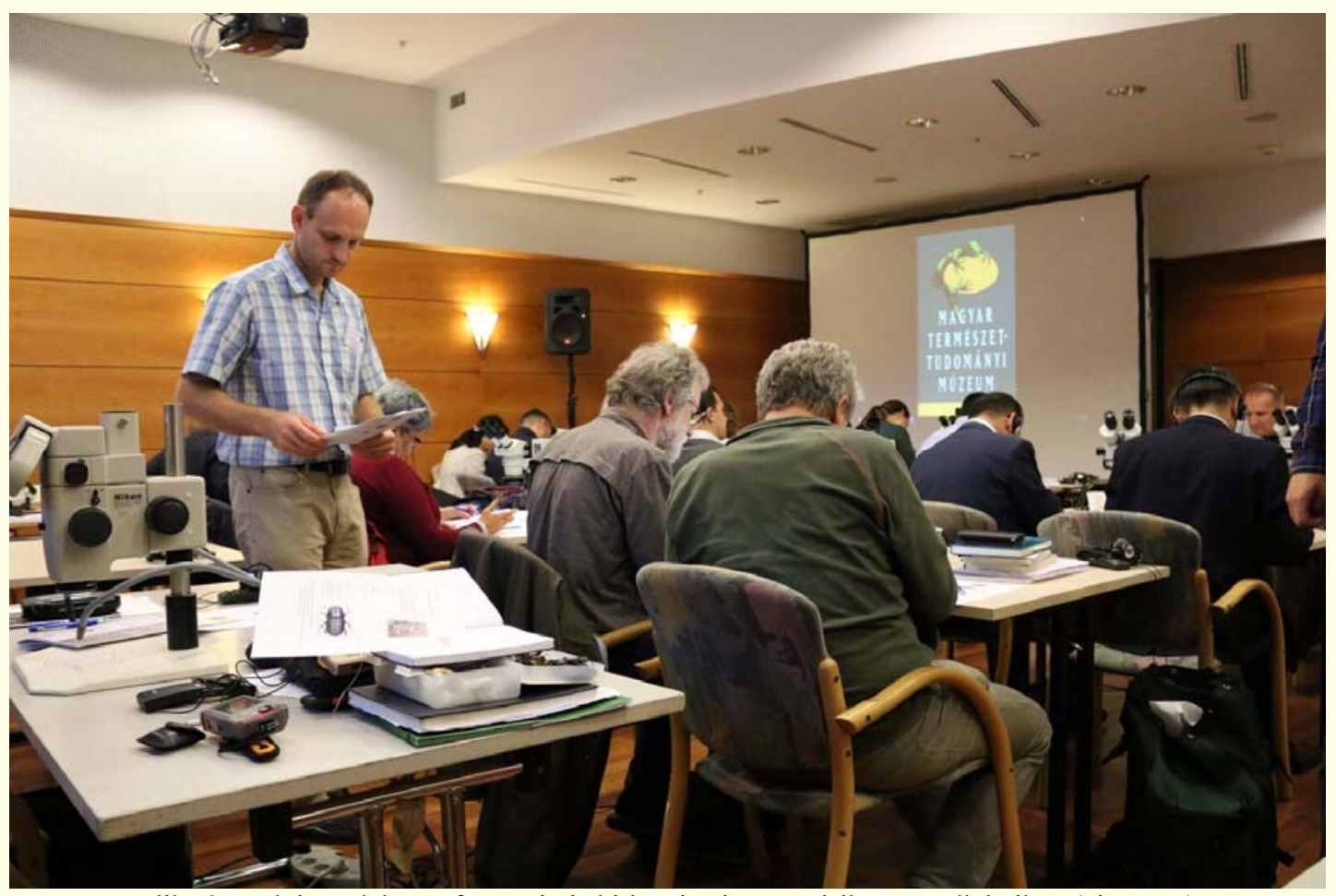

Slika 2: Praktično delo z referenčnimi zbirkami najnevarnejših vrst podlubnikov (vir: FAO)

Drugi dan smo začeli s predavanji o invazivnih vrstah na Madžarskem. Spoznali smo invazivne vrste sesalcev, njihov vpliv in možnosti upravljanja, na primeru zlatega šakala (Canis aureus (Linnaeus, 1758)) pa so nam predstavili raziskavo, s katero so ugotavljali, ali na invazivnost vrste vplivajo klimatske spremembe ali dostopnost hrane. V razmislek nam je bilo predavanje o problematiki urbanega gozdarstva, kjer vladata velika vrzel v strokovni usposobljenosti vseh, ki delajo na tem področju, in pomanjkanje pravilne komunikacije. Precej skrb zbujajoče je bilo predavanje o vplivih višanja temperatur, upadanja količine padavin in vse večjih nihanj temperaturnega in padavinskega režima, ki so jim pretežno nižinska območja Evrope in Srednje Azije še posebej izpostavljena. Predavatelj je poudaril, da je gozdarsko prakso treba usmerjati v vzpostavljanje odpornih gozdnih sestojev in da moramo kljub vsemu biti pripravljeni na presenečenja. V mnogih primerih se bo treba sprijazniti, da gozdovi ne bodo obstali, in treba se bo odločiti med gozdnimi nasadi in naravi prepuščenimi območji, kjer se bodo po naravni poti vzpostavili drugačni ekosistemi, odporni na nove klimatske razmere. Za konec je bilo na primerih invazivnih vrst žuželk na Madžarskem nazorno prikazano, da se posamezne invazivne vrste v novem okolju obnašajo povsem različno, zato je vsako novo vrsto treba obravnavati individualno. Predavanja so udeležence spodbudila $\mathrm{k}$ razmisleku in živahnim diskusijam v predavalnici in med odmori.

Po predavanjih smo se pogovarjali o izkušnjah in pričakovanjih posameznih držav od povezave REUFIS in aktualni problematiki na področju invazivnih vrst v gozdovih. Udeleženci smo si bili enotni, da REUFIS nedvomno pomeni korak naprej pri spopadanju z izzivi na področju invazivnih vrst v gozdovih. Srečanje je udeležence navdajalo z optimizmom, od povezave pa si obetamo izmenjavo informacij in dobrih praks ter aktivno sodelovanje na različnih področjih invazivnih vrst $\mathrm{v}$ gozdovih. REUFIS je pomemben tudi zato, ker povezuje Evropo z rusko govorečimi državami, s čimer je narejen velik premik tudi pri podiranju jezikovnih ovir, ki so nemalokrat vzrok za neuspešno komunikacijo in onemogočajo plodno sodelovanje (slika 3). 


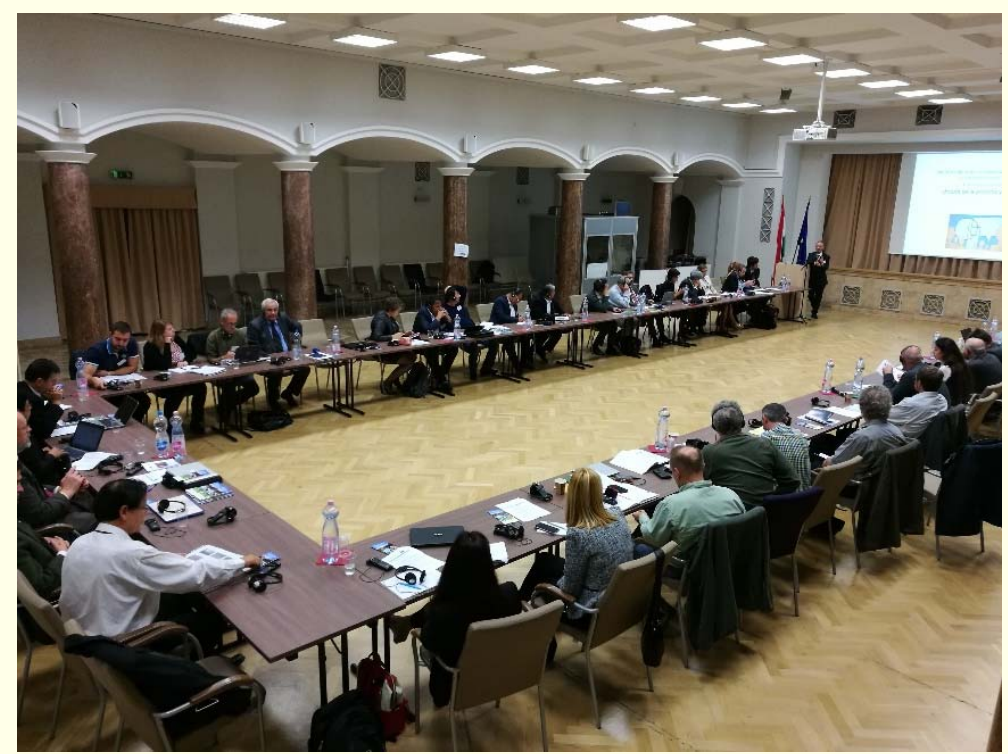

Slika 3: Udeleženci inavguracijskega srečanja REUFIS med predavanji (foto: A. Kavčič)

Zadnji dan smo uradno potrdili statut REUFIS ter izvolili predsednika in izvršni odbor. Predstavljena je bila tudi uradna spletna stran REUFIS, ki bo začela delovati $\mathrm{v}$ naslednjih nekaj tednih. Načrt dela z vsemi aktivnostmi bo pripravljen v začetku leta 2018 .

Tridnevno srečanje smo zaključili s terenskim delom, kjer smo si v okolici mesta Gödöllő ogledali gozdni sestoj invazivne robinije in arboretum. Na Madžarskem imajo v gozdovih velik delež invazivnih vrst dreves, ki so posledica načrtnega in intenzivnega pogozdovanja $\mathrm{v}$ šestdesetih letih prejšnjega stoletja. Sedaj te vrste uporabljajo za različne namene, robinijo v glavnem za les za kurjavo. Zelo velik problem na Madžarskem predstavlja obnova gozda, saj zaradi velikega števila parkljaste divjadi ta skoraj ni več mogoča po naravni poti. Da divjadi preprečijo uničenje mladih rastlin, imajo zato ograjene večje gozdne površine.
Zelo zanimiv je bil tudi arboretum, ki meri 350 ha in vsebuje 154 različnih sestojev. Ustanovljen je bil leta $1902 \mathrm{z}$ namenom, da bi ugotovili, katere tujerodne vrste dreves bi bile najbolj uporabne za pogozdovanje in različne namene $\mathrm{v}$ gozdarstvu. $\mathrm{V}$ arboretumu je mogoče najti veliko različnih vrst, podvrst in varietet iglavcev (147) in listavcev (875). Arboretum danes služi kot genska banka in raziskovalni objekt, del pa je namenjen tudi javnosti za rekreacijo (slika 4).

Udeleženci smo bili nad celotnim tridnevnim programom navdušeni in razšli smo se v pričakovanju začetka aktivnega in plodnega sodelovanja na področju invazivnih vrst v gozdovih na območju Evrope in Srednje Azije. Veselimo se že tudi naslednjega srečanja REUFIS, ki bo naslednje leto v Belorusiji.

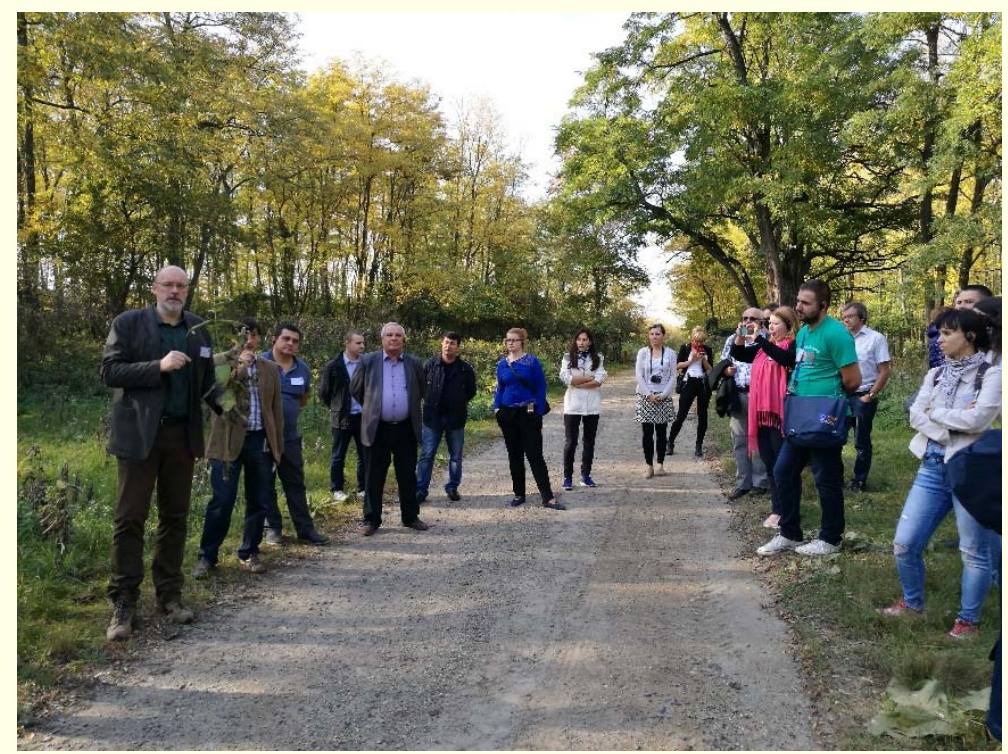

Slika 4: Terenski del srečanja (foto: A. Kavčič) 